\title{
BcSUN1, a B. cinerea SUN-Family Protein, Is Involved in Virulence
}

\author{
Alicia Pérez-Hernández¹, Mario González ${ }^{1}$, Celedonio González ${ }^{1}$, Jan A. L. van Kan² and \\ Nélida Brito ${ }^{1 *}$ \\ 1 Departamento de Bioquímica, Microbiología, Biología Celular y Genética, Universidad de La Laguna (ULL), La Laguna, \\ Spain, ${ }^{2}$ Laboratory of Phytopathology, Department of Plant Sciences, Wageningen University and Research Centre (WUR), \\ Wageningen, Netherlands
}

BcSUN1 is a glycoprotein secreted by Botrytis cinerea, an important plant pathogen that causes severe losses in agriculture worldwide. In this work, the role of BcSUN1 in different aspects of the $B$. cinerea biology was studied by phenotypic analysis of Bcsun 1 knockout strains. We identified BcSUN1 as the only member of the Group-I SUN family of proteins encoded in the $B$. cinerea genome, which is expressed both in axenic culture and during infection. BcSUN1 is also weakly attached to the cellular surface and is involved in maintaining the structure of the cell wall and/or the extracellular matrix. Disruption of the Bcsun1 gene produces different cell surface alterations affecting the production of reproductive structures and adhesion to plant surface, therefore reducing

OPEN ACCESS

Edited by:

Helio K. Takahashi,

Federal University of São Paulo (USP),

Brazil

Reviewed by:

Luciana Lopes Guimaraes,

Universidade Santa Cecilia, Brazil Anderson Messias Rodrigues, Federal University of São Paulo (USP),

Brazil

*Correspondence:

Nélida Brito

nbrito@ull.edu.es

Specialty section: This article was submitted to Fungi and Their Interactions,

a section of the journal

Frontiers in Microbiology

Received: 14 November 2016 Accepted: 06 January 2017 Published: 20 January 2017

Citation:

Pérez-Hernández A, González M González C, van Kan JAL and Brito N (2017) BcSUN1, a B. cinerea SUN-Family Protein, Is Involved in Virulence. Front. Microbiol. 8:35. doi: 10.3389/fmicb.2017.00035
$B$. cinerea virulence. BcSUN1 is the first member of the SUN family reported to be involved in the pathogenesis of a filamentous fungus.

Keywords: Botrytis cinerea, BcSUN1, glycoprotein, secretome, cell wall, virulence

\section{INTRODUCTION}

Botrytis cinerea has been considered the second most important plant pathogenic fungus according to its economic/scientific importance (Dean et al., 2012). During infection of plant tissues, the fungus secretes hundreds of proteins to the extracellular medium, although just a few of them have been reported, by analysis of the corresponding mutants, to have a significant contribution to B. cinerea virulence (González et al., 2015).

BcSUN1 is a member of the $\beta$-glucosidase SUN family that has been experimentally identified as a component of the B. cinerea secretome (Espino et al., 2010; González et al., 2014). The Bcsun1 gene encodes a protein of 471 amino acids that contains a signal peptide for secretion, as well as several Ser/Thr-rich regions that are potentially hyper-O-glycosylated (González et al., 2012). Oligosaccharides with mannose $\alpha 1-2$ and/or $\alpha 1-3$ bonds, but not mannose $\alpha 1-6$ bonds, were experimentally confirmed to be present in the BcSUN1 protein (González et al., 2014). In addition, the culture medium from a $B$. cinerea strain overexpressing BcSUN1 showed an enhanced capacity to elicit plant defenses, as compared with the wild type strain (González et al., 2014), suggesting that BCSUN1 may be recognized by the plant immune system.

The $\beta$-glucosidase SUN family of proteins (Pfam PF03856; Interpro IPR005556) were first described in Saccharomyces cerevisiae and have been identified only in ascomycetes (Firon et al., 2007). In spite of their annotation, $\beta$-glucosidase activity has been described only for AfSUN1 from Aspergillus fumigatus and SUN41 from Candida albicans, assigned to the new Glycosyl Hydrolase family GH132 (Gastebois et al., 2013). Structurally, proteins of this family are classified into two groups (Firon et al., 2007). Group-I members show a well conserved $C$-terminal region of 258 
amino acids corresponding to the SUN domain, which comprises four putative $\mathrm{Fe}$-binding cysteine residues (Cys- $\mathrm{X}_{5}-\mathrm{Cys}-\mathrm{X}_{3}$ Cys- $\mathrm{X}_{24}$-Cys) (Mouassite et al., 2000a), and a less conserved $\mathrm{N}$-terminal region, which contains a signal peptide and a low complexity region rich in Ser and Thr residues. Group-II proteins harbor a degenerate SUN domain, with multiple amino acid insertions in the Cys-rich motif and a shorter $N$-terminal region (Firon et al., 2007; Gastebois et al., 2013). Members of Group-II are all related to the $S$. cerevisiae YMR244W protein (Firon et al., 2007).

Group-I members have been extensively studied in yeast, and diverse biological functions have been attributed to them. The four prototypical SUN proteins of $S$. cerevisiae namely SIM1, UTH1, NCA3 and SUN4 (Mouassite et al., 2000a,b) are involved in different cell functions. SIM1 plays an important role in the regulation of DNA replication (Dahmann et al., 1995), although when overproduced from a multicopy plasmid, SIM1 also functioned as an extracellular suppressor of mutations in the PAG1 and CBK1 genes involved in cellular morphogenesis (Du and Novick, 2002). UTH1 was first identified in a screening for S. cerevisiae mutants with increased stress resistance and longer life spans (Kennedy et al., 1995) and shows a dual localization: in mitochondria, where it is involved in mitochondrial biogenesis and autophagy (Camougrand et al., 2000) and in the cell wall, where it seems to play a role in determining the $\beta$ d-glucan/chitin composition (Ritch et al., 2010). The third member of the family, NCA3, is involved in the maturation of transcripts encoding two components of the ATP-synthase complex in mitochondria (Pelissier et al., 1995). Finally, SUN4 was isolated as a soluble cell wall protein (Cappellaro et al., 1998) and is involved in cell septation (Mouassite et al., 2000a). Similarly to UTH1, SUN4 has also been found both in the cell wall and in mitochondria (Cappellaro et al., 1998; Mouassite et al., 2000a). Recently, UTH1, SIM1 and SUN4 have also been described as secreted proteins, and their production was affected by the level of oxygen (Kuznetsov et al., 2013). In C. albicans, on the contrary, only two members of the SUN family have been identified, SUN41 and SUN42, both of which are involved in remodeling the cell wall and are essential for cell separation (Firon et al., 2007; Hiller et al., 2011).

The SUN family has been poorly studied in filamentous fungi. To our knowledge, these proteins have been experimentally analyzed only in A. fumigatus (Gastebois et al., 2013), a saprophytic fungus typically found in soil and decaying organic matter, which can also cause aspergillosis in humans (KwonChung and Sugui, 2013), and in Ustilaginoidea virens, the causal agent of rice false smut disease (Yu et al., 2015). AfSUN1 from A. fumigatus, a member of Group-I, has been reported to be involved in fungal morphogenesis (Gastebois et al., 2013) and the Group-II protein, UvSUN2 from $U$. virens, has been proposed to be involved in cell wall biogenesis and response to stress (Yu et al., 2015).

In this work we report the disruption of the Bcsun 1 gene in $B$. cinerea and the phenotypic characterization of the mutant. We show that BcSUN1 plays a key role in fungal morphogenesis and is required for full virulence.

\section{MATERIALS AND METHDOS}

\section{Strains and Growth Conditions}

Botrytis cinerea strains used in this work were B05.10 (Quidde et al., 1999), a wild type strain, and B05.10-BcSUN1, which expresses a tagged version of the BcSUN1 protein under the control of the OliC promoter (González et al., 2014). These were kept as conidial suspensions in $15 \%$ glycerol at $-80^{\circ} \mathrm{C}$ for long storage, and were maintained on 3\% malt extract agar (MEA, Oxoid, UK) plates for routine use. Fungal cultures were routinely incubated at $22^{\circ} \mathrm{C}$. B. cinerea conidia were prepared as described by Benito et al. (1998) from cultures on tomatoplates (25\% homogenized tomato fruits, $1.5 \%$ agar, $\mathrm{pH} 5.5$ ). Unless otherwise indicated, fungal strains were grown on YGG medium $[0.5 \%$ yeast extract, $2 \%$ glucose, and $0.3 \%$ Gamborg's B5 (Duchefa Biochemie, The Netherlands)], supplemented with $1.5 \%$ agar and $100 \mu \mathrm{g} / \mathrm{ml}$ hygromycin or nourseothricin when required. As minimal medium, GB5 (0.3\% Gamborg's B5, 1\% glucose, $10 \mathrm{mM} \mathrm{KH}_{2} \mathrm{PO}_{4}$ ) was used. To examine production of the extracellular matrix (ECM) under the microscope, conidia were germinated in PDB medium (0.1\% Potato dextrose broth, Duchefa Biocheme, The Netherlands). To analyze different extracellular protein fractions, conidia were germinated in YGG-L medium (0.3\% Gamborg's B5, 0.36\% glucose, $10 \mathrm{mM}$ $\mathrm{KH}_{2} \mathrm{PO}_{4}, 10 \mathrm{mM}$ MES (Sigma Aldrich, USA), 0.5\% yeast extract, $\mathrm{pH}$ 5.5).

Nicotiana tabacum var. Havana, Solanum lycopersicum var. moneymaker and Phaseolus vulgaris plants were maintained in a growth chamber at $22^{\circ} \mathrm{C}, 70 \%$ humidity with a light/dark cycle of $14 \mathrm{~h}$ light/10 h dark. When tobacco seedlings were required, seeds were sterilized as explained before (González et al., 2014) and incubated 2 days at $4^{\circ} \mathrm{C}$ in darkness to break dormancy before germination on solid MS medium [0.5\% Murashige and Skoog (Duchefa Biochemie, The Netherlands), 0.8\% agar, $\mathrm{pH}$ 5.7] for 1 week.

\section{Quantitative Real-Time PCR (Q-RT-PCR)}

Mycelia for RNA extraction were prepared as described elsewhere (ten Have et al., 2010). Briefly, $7 \times 10^{6}$ conidia/ml were germinated for $12 \mathrm{~h}$ in $250 \mathrm{ml}$ of GB5 medium containing $2 \mathrm{mM}$ sucrose instead of glucose and a dialysis bag with $30 \mathrm{ml}$ of a $50 \%(\mathrm{w} / \mathrm{v})$ kiwi, tomato or strawberry fruit extract (made in the same medium). As a control, standard GB5 medium was used and no dialysis bag was added. For the in planta expression studies, RNA was isolated from infected tomato leaves as described before (Brito et al., 2006).

One microgram of total RNA was used as template for cDNA synthesis using the iScript cDNA Synthesis Kit (BioRad, USA), according to the manufacturer's instructions. Q-RTPCR reactions were performed in an iCycler iQ thermal cycle (Bio-Rad, USA) with the iQ SYBR Green Supermix (BioRad, USA) and the primers listed in Supplementary Table S1. In order to normalize the expression levels, the $B$. cinerea act $A$ gene was used as an internal reference. One of the two primers for each transcript spanned over an exonexon junction on the cDNA to avoid amplification from contaminant genomic DNA. The relative mRNA amounts 
were calculated by the $\Delta \Delta \mathrm{Ct}$ method from the mean of three independent determinations of the threshold cycle $(\mathrm{Ct})$, and the control sample (ungerminated conidia) was used as calibrator (Schmittgen and Livak, 2008). Deviation from the mean for each sample was calculated from the standard deviation (SD) in the $\Delta \Delta \mathrm{Ct}$ value using the expression

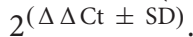

\section{Bcsun1 Gene Disruption}

The replacement cassette was constructed by Overlap Extension PCR as described by Nelson and Fitch (2011), with some modifications, and the strategy is outlined in Supplementary Figure S1. Genomic DNA from B. cinerea was extracted using the PUREGENE DNA Purification Kit (Qiagen, USA) and primers (Supplementary Table S1) were from Biolegio (Nijmegen, The Netherlands). All PCR products and restriction endonuclease digestion fragments were purified with PCR Cleanup Kit and NucleoSpin Gel kit (MACHEREY-NAGEL, Germany), respectively. The two fragments homologous to the target gene were amplified with GoTaqG2 DNA Polymerase (Promega, USA) and primer pairs 6.5.1/6.5.3 for the $5^{\prime}$-flanking region, and 6.3.1/6.3.3 for $3^{\prime}$-flanking region. The hygromycin resistance cassette was obtained by digestion of the pLOB7 vector (Zhang et al., 2011) with EcoRI and HindIII. The three fragments were fused by PCR using the Expand High Fidelity Enzyme Mix (Roche, Switzerland). The resultant gene replacement cassette was purified, checked by double digestions with EcoRI-SacII and HindIII-SacII, and used to transform B. cinerea protoplasts (van Kan et al., 1997). Homokaryons were purified from the transformants obtained and analyzed by Southern blot and PCR (Supplementary Figure S1). Two independent knockout lines ( $\Delta B$ csun 1.1 and $\Delta B$ csun 1.2) were used in all experiments. Since the phenotypes of both independent mutants were identical, only the results of $\Delta B c s u n 1.1$ are shown in most figures for simplicity.

\section{Phenotypic Analysis}

Fungal sensitivity to a range of compounds was assayed determining the growth rate on YGG plates supplemented with one of the following chemicals: $30 \mathrm{mM} \mathrm{H}_{2} \mathrm{O}_{2}$ (Foret, Spain), $0.005 \%$ congo red (CR; Sigma-Aldrich, USA), 0.02\% SDS, 0.05\% Calcofluor white (CW; Sigma-Aldrich, USA), $1 \mathrm{M}$ sorbitol, or $0.4 \%$ boric acid (BA; Merck-Millipore, Germany). Colony radius was measured every $24 \mathrm{~h}$ during 3 days.

Sensitivity of mycelium to protoplast-forming enzymes was analyzed by treating young mycelium with Lysing Enzymes from Trichoderma harzianum (Sigma-Aldrich, USA). Conidia were germinated for $16 \mathrm{~h}$ in YGG medium, washed three times with $\mathrm{KC}$ buffer $(0.6 \mathrm{M} \mathrm{KCl}, 50 \mathrm{mM} \mathrm{CaCl}$ ), and incubated for up to $4 \mathrm{~h}$ in $7.5 \mathrm{mg} / \mathrm{ml}$ of the enzyme mix in KC buffer. Samples were taken every $30 \mathrm{~min}$ and protoplasts were counted using a haemocytometer.

The capacity of the mycelium to retain water was calculated by comparing the fresh weight of the mycelium after filtration with the dry weight after being completely dried. Fungal strains were grown for 3 days in $20 \mathrm{ml}$ of YGG medium in the dark, without shaking. Cultures were then filtered and the mycelia were allowed to drain for $30 \mathrm{~min}$ at room temperature and weighed (fresh weight) and then dried at $60^{\circ} \mathrm{C}$ to a constant weight (dry weight). The water retention capacity was calculated as the ratio of the amount of water retained (fresh weight minus dry weight) to the corresponding dry weight.

Pathogenicity tests were performed by inoculating bean, tomato or tobacco leaves with either agar plugs containing young mycelium (0.2-cm YGG-agar cubes) or conidia suspensions $(5-\mu 1$ droplets of $2.5 \times 10^{5}$ conidia/ml in TGGK solution $(60 \mathrm{mM}$ $\mathrm{KH}_{2} \mathrm{PO}_{4}, 10 \mathrm{mM}$ glycine, $0.01 \%$ Tween $20,100 \mathrm{mM}$ glucose). The inoculated leaves were incubated at $20^{\circ} \mathrm{C}$ under conditions of high humidity on water-soaked filter paper in closed containers. At different time points after inoculation, lesions on leaves were photographed and their radii were measured. Quantitative results are presented as the percentage of expanding lesions per total number of inoculation spots, and the rate of increase of lesion size (in $\mathrm{cm} /$ day) of the expanding lesions. Adhesion of B. cinerea to plant surfaces was assayed as described by González et al. (2013). The number of conidia on infected leaves was estimated at 10 days post-inoculation using squares of infected leaf $(4 \times 4 \mathrm{~cm})$. Conidia were released by vortexing in $\mathrm{ddH}_{2} \mathrm{O}$ for $20 \mathrm{~s}$ and then quantified as described elsewhere (González et al., 2013).

To compare the amount of ECM around hyphae, the fungus was grown for 3 days in $500 \mu$ l of PDB medium (inoculated with $5 \times 10^{5}$ conidia), on glass slides in high-humidity conditions. The medium was then aspirated and the mycelium was completely overlaid with several drops of black India ink, covered with a coverslip, and observed under the microscope (Olympus BX-50). Aggregation of conidia was observed under the microscope at $2 \mathrm{~h}$ after inoculation in YGG medium. To analyze the production of conidiophores and infection cushions, agar plugs with young mycelium were laid on glass slides and incubated 10 days under high-humidity before observation under the microscope. To quantify the number of germ tubes per conidium and their rate of ramification, conidia were germinated for $16 \mathrm{~h}$ in YGG medium and observed under the fluorescence microscope after staining with $\mathrm{CW}$ for easier visualization. Staining was done by incubation in a $\mathrm{CW}$ solution $(0.05 \% \mathrm{CW}$ in $3.75 \% \mathrm{KOH})$ for $5 \mathrm{~min}$, washing twice with $15 \% \mathrm{KOH}$, and resuspension in $20 \mu \mathrm{l}$ of $3.75 \% \mathrm{KOH} / 4.35 \%$ glycerol. The microscope (Olympus BX-50) was equipped with a U-MWIB filter.

Production of reactive oxygen species (ROS) by fungal strains was assayed according to Viefhues et al. (2015) with minor modifications. Briefly, YGG-agar solid medium was overlaid with cellophane, inoculated with mycelium plugs, incubated for 4 days, and finally used to harvest $6 \mathrm{mg}$ of fresh mycelium that was then placed at the bottom of a well in a microtiter (96 wells) plate. Then $250 \mu \mathrm{l}$ of a 3,3'-Diaminobenzidine (DAB) solution $(0.5 \mathrm{mg} / \mathrm{ml} \mathrm{DAB}$ in $100 \mathrm{mM}$ citric acid, $\mathrm{pH} 3.7)$ were added to cover the mycelium, and the plate was incubated for $1.5 \mathrm{~h}$ in the dark and visually evaluated. Positive and negative controls were done as in Viefhues et al. (2015). Production of ROS during infection was assayed in tobacco leaves inoculated with $5-\mu l$ droplets of a conidial suspension $\left(5 \times 10^{5}\right.$ conidia/ml in TGGK solution). $40 \mathrm{~h}$ after inoculation, leaf disks with the infected area in its center were cut and vacuum infiltrated for $1 \mathrm{~h}$ with $1 \mathrm{mg} / \mathrm{ml}$ 
DAB, pH 3.8. To visualize the ROS stain, disks were then boiled in ethanol for $5 \mathrm{~min}$ to eliminate chlorophyll, and photographed. Quantification of ROS from the images obtained was done with the software Fiji (Schindelin et al., 2012) and is expressed as the percentage of brown pixels detected in a circumference of constant area around the infection point.

\section{Extracellular Protein Fractions and BcSUN1 Localization}

The strain B05.10-BcSUN1 was grown for $16 \mathrm{~h}$ with shaking (160 rpm) in YGG-L medium supplemented with $25 \mu \mathrm{g} / \mathrm{ml}$ nourseothricin and $4 \mu \mathrm{g} / \mathrm{ml}$ pepstatin-A (Sigma-Aldrich, USA), inoculated with $3 \times 10^{6}$ conidia/ml. Three protein fractions were recovered from the culture: (i) the extracellular proteins were recovered from culture filtrates; (ii) proteins non-covalently attached to the fungal cells were isolated incubating the collected mycelium with $300 \mathrm{mM} \mathrm{NaCl}$ (15 ml/g mycelium) for $15 \mathrm{~min}$ and subsequent filtration, recovering the $\mathrm{NaCl}$ solubilized proteins; and (iii) the remaining mycelial proteins were obtained by incubation of the NaCl-treated mycelium with Laemmli sample buffer (Laemmli, 1970) (0.1 mg mycelium in $100 \mu \mathrm{l}$ buffer). Extracellular and $\mathrm{NaCl}$-solubilized proteins were precipitated with methanol-chloroform according to Wessel and Flügge (1984) and the pellets were also resuspended in Laemmli sample buffer. The three protein preparations were fractionated by SDS-PAGE, electroblotted onto nitrocellulose membranes (Whatman Protran BA 85), and BcSUN1 was detected with mouse anti-c-myc antibodies (Sigma-Aldrich, USA; 1:5000 dilution) in combination with anti-mouse IgG conjugated to Horseradish peroxidase (Sigma-Aldrich, USA; 1:3000 dilution) as the secondary antibody. The peroxidase signal was detected with Immobilon Western Chemiluminescent HRP Substrate (Merk-Millipore, Germany) and the intensity of the bands was measured with the software Quantity One (BioRad, USA).

\section{Statistical Analysis}

Statistical analysis was carried out with SPSS 17 (IBM). Statistical significance tests used were either the $T$-test, in those cases with a normal distribution (analyzed with the Kolmogorov-Smirnov test), or the Mann-Whitney test, if sample distribution was not normal. Asterisks indicate a statistically significant difference with the control (wild type strain) $(p=0.05)$.

\section{RESULTS}

\section{BcSUN1 Is the Only Member of the Group-I of SUN Family in B. cinerea}

BcSUN1 (Bcin06g06040.1, from the $B$. cinerea protein database in EnsemblFungi ${ }^{1}$; van Kan et al., 2016) is a highly glycosylated protein of $48 \mathrm{kDa}$, initially identified as a component of the $B$. cinerea early secretome (Espino et al., 2010) and also present in the glycosecretome (González

${ }^{1}$ http://fungi.ensembl.org/Botrytis_cinerea et al., 2014). The alignment of its sequence with the four S. cerevisiae proteins that belong to Group-I of the SUN family (Supplementary Figure S2) showed an overall identity ranging from $28.1 \%$ for NCA3 to $38.6 \%$ for SIM1 (Table 1), while sequence conservation was higher for the $C$-terminal region containing the SUN domain, with amino acid sequence identities ranging from 41 to $46 \%$. Analysis of the hydropathic profiles (Supplementary Figure S3) also established a good similarity to Group-I proteins, especially at the $C$-terminus. BcSUN1 is especially similar to AfSUN1 from A. fumigatus (43.5\% of amino acid identity), the only member of Group-I experimentally studied in filamentous fungi (Gastebois et al., 2013).

A BLAST-P search (Altschul et al., 1997) in the B. cinerea genome $^{1}$ with BcSUN1 as the query sequence did not identify additional homologues belonging to Group-I. However, the search revealed an additional SUN family member (gene Bcin07g06600.1) showing 53\% amino acid identity both with the hypothetical protein YMR244W from S. cerevisiae and $\beta$-glucosidase Adg3 from Schizosaccharomyces pombe, both classified as members of the Group-II of the SUN family (Firon et al., 2007). This gene encodes a protein of 530 amino acids containing a signal sequence for secretion, according to SignalP 4.1, and a degenerate SUN domain, with multiple amino acid insertions in the $\mathrm{N}$-terminal Cys-rich motif (data not shown).

\section{BcSUN1 Is Expressed Both in Axenic Culture and In planta}

BcSUN1 has been detected in the culture medium, as a secreted protein, very early after conidial germination and also at 4 days after inoculation on YGG (Espino et al., 2010; González et al., 2014). The expression of the Bcsun 1 gene was studied in more detail in this work by Q-RT-PCR. In axenic culture, Bcsun1 mRNA levels increased significantly in every condition tested at $12 \mathrm{~h}$ post inoculation, as compared with the expression in non-germinated conidia (Figure 1A). The level of induction was higher when plant extracts were included in the medium than in a chemically defined medium with glucose as the only carbon source. The levels of Bcsun 1 mRNA also increased during the infection of tomato leaves with $B$. cinerea (Figure 1B). A slight

TABLE 1 | Amino acid sequence identity and similarity of BcSUN1 to S. cerevisiae proteins in Group-I of the SUN family.

\begin{tabular}{lccccc}
\hline & \multicolumn{2}{c}{ Protein } & & \multicolumn{2}{c}{ C-terminal region } \\
\cline { 2 - 3 } \cline { 5 - 6 } & Identity (\%) & Similarity (\%) & & Identity (\%) & Similarity (\%) \\
\hline SIM1 & 38.6 & 52.9 & & 41.6 & 58.0 \\
UTH1 & 36.6 & 47.9 & & 46.2 & 57.3 \\
NCA3 & 28.1 & 41.0 & & 43.0 & 58.3 \\
SUN4 & 33.7 & 48.6 & & 43.4 & 57.5 \\
\hline
\end{tabular}

Identity and similarity were computed with EMBOSS Needle from alignments of the entire sequences or the C-terminal regions only. Uniprot accession numbers for the S. cerevisiae proteins are as follows: P40472 (SIM1), P36135 (UTH1), P32493 (NCA3) and P53616 (SUN4). 

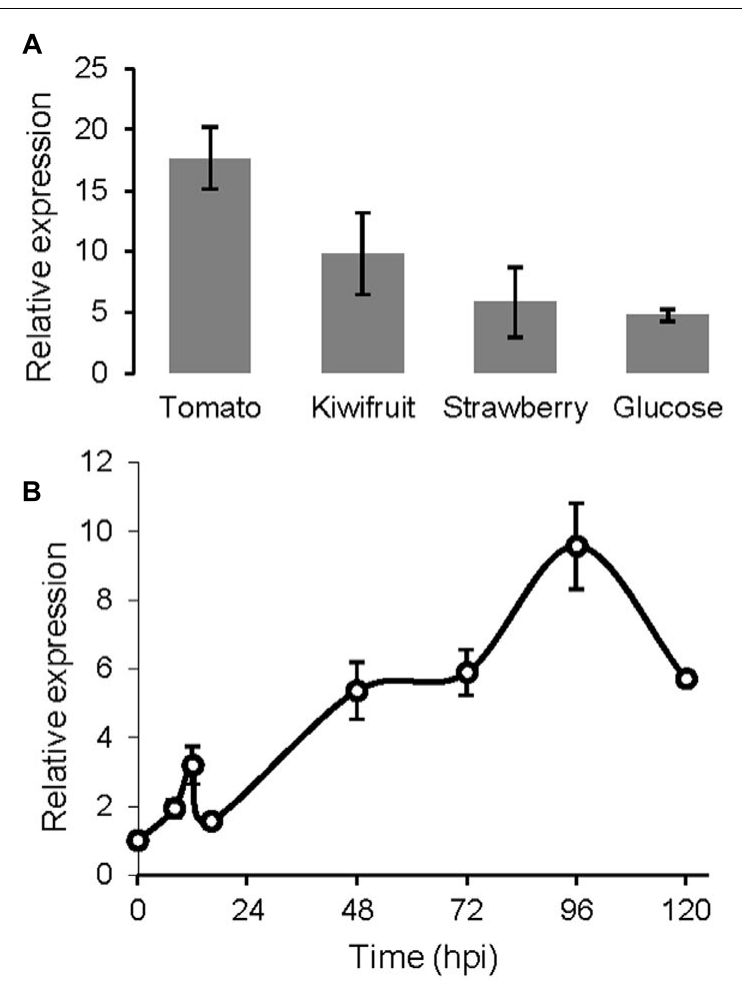

FIGURE 1 | Levels of Bcsun1 mRNA in the wild type strain B05.10 under different growth conditions. (A) Levels of Bcsun1 mRNA in the wild type strain B05.10 grown for $12 \mathrm{~h}$ in liquid GB5 medium containing, as indicated, a dialysis bag with $50 \%$ (w/v) kiwi, tomato or strawberry fruit extract, or supplemented with $1 \%$ glucose as carbon source. (B) Levels of Bcsun 1 mRNA in tomato leaves infected with B. cinerea B05.10 at various hours after inoculation (hpi). In all cases data are relative to the mRNA levels in ungerminated conidia. Results are expressed as mean \pm SD of 3 technical replicates.

induction ( 2.5 times in comparison to ungerminated conidia) was observed in the early phase of infection (up to $12 \mathrm{~h}$ ) and then, after a slight drop, expression levels increased up to $96 \mathrm{~h}$ post inoculation (Figure 1B). These results suggest a role for BcSUN1 during infection, especially at late stages when the lesions become necrotic.

\section{BcSUN1 Is Involved in Maintaining Cell Wall Integrity}

Two independent Bcsun1 knockout mutants ( $\Delta B \operatorname{csun} 1.1$ and $\Delta B c s u n 1.2)$ were generated and characterized by PCR and Southern-blot (Supplementary Figure S1). The two mutants showed no difference with the wild type in the growth rate in rich or minimal media and no difference was found either in media supplemented with tomato leaf or fruit extracts (Figure 2A). Nevertheless, the addition of various compounds known to affect the integrity of the plasma membrane or the cell wall integrity did affect the growth rates of the mutant strains (Figure 2A). Calcofluor white, congo red, boric acid, and SDS caused a slight, but significant reduction in the growth rate of the $\Delta B \operatorname{csun} 1$ strains, suggesting that BcSUN1 may have a role in the biogenesis or stability of the cell wall. A smaller growth rate caused by a weaker cell wall can usually be recovered by the addition of osmotic stabilizers to the growth medium. However, in the case of the $\Delta B \operatorname{csun} 1$ mutants, the presence of an osmotic stabilizer ( $1 \mathrm{M}$ sorbitol) had a negative effect on growth, and had almost the same impact on the growth rate as CW, CR or boric acid (Figure 2A).

Defects in cell wall structure in filamentous fungi can be visualized by testing the sensitivity to protoplast-forming enzymes. With this purpose, young mycelia (conidia germinated for $16 \mathrm{~h}$ ) were incubated with a cocktail of cell wall degrading enzymes and the production of protoplasts was monitored. The $\Delta B$ csun 1 mutant strains were more sensitive to these enzymes than the wild type (Figure 2B), again pointing to an altered cell wall caused by the deletion of Bcsun1. These modifications may also be the reason for the changes detected for the $\Delta B c s u n 1$ mutants in the number of germ tubes per conidium (Figure 2C) and in the branching pattern of young hyphae (Figure 2D), as an altered cell wall could potentially have an impact on whether or not a new ramification forms at a given moment.

\section{Deletion of Bcsun1 Induces Cell Surface Alterations and Modifies the Production of Reproductive Structures}

Although BcSUN1 seems to have a role in the integrity of the cell wall, the protein is also found in the extracellular medium, raising the possibility of its involvement in the structure or metabolism of the ECM. To examine this hypothesis, the $\Delta B c s u n 1$ mutants were grown for 3 days in PDB medium and ECM was negatively stained with India ink (González et al., 2013). ECM is observed as a clear halo surrounding the hyphae against the dark background. The halo was much smaller for the $\Delta B \operatorname{csun} 1$ strains (Figure 3A), as compared with the wild type. One of the functions proposed for the ECM is the retention of water in the cell vicinity (Laspidou and Rittmann, 2002), and a reduced ECM could result in the reduction of the amount of water retained by the mycelium upon filtration of the fungal cultures. Indeed the mycelium of $\Delta B$ csun 1 strains retained almost $50 \%$ less water than the wild type (Figure 3B) in agreement with the reduced ECM halo detected by India ink staining (Figure 3A).

Additionally, ECM has been proposed to have a role in cellto-cell attachment (Doss et al., 1995), and therefore the incidence of conidial aggregation was assessed. In the case of the $\Delta B \operatorname{csun} 1$ mutants most conidia (75\%) were found associated to at least one other, while the majority of wild type spores appeared to be in the suspension as individual conidia (Figure 3C). Finally, cell surface modifications could provoke differences in the colony morphology, especially at the borders. When fungal strains were grown in MEA medium for 3 days, the mutants showed more irregular and diffuse colony margins as compared to the wild type (Figure 3D).

The influence of the deletion of Bcsun1 on the production of conidia was assessed determining the number of conidia produced by the two $\Delta B$ csun 1 mutants, as compared to the wild type (Figures $4 \mathbf{A}, \mathbf{B}$ ), but also by studying the number of conidiophores along mature hyphae (Figures 4C,D). The results 

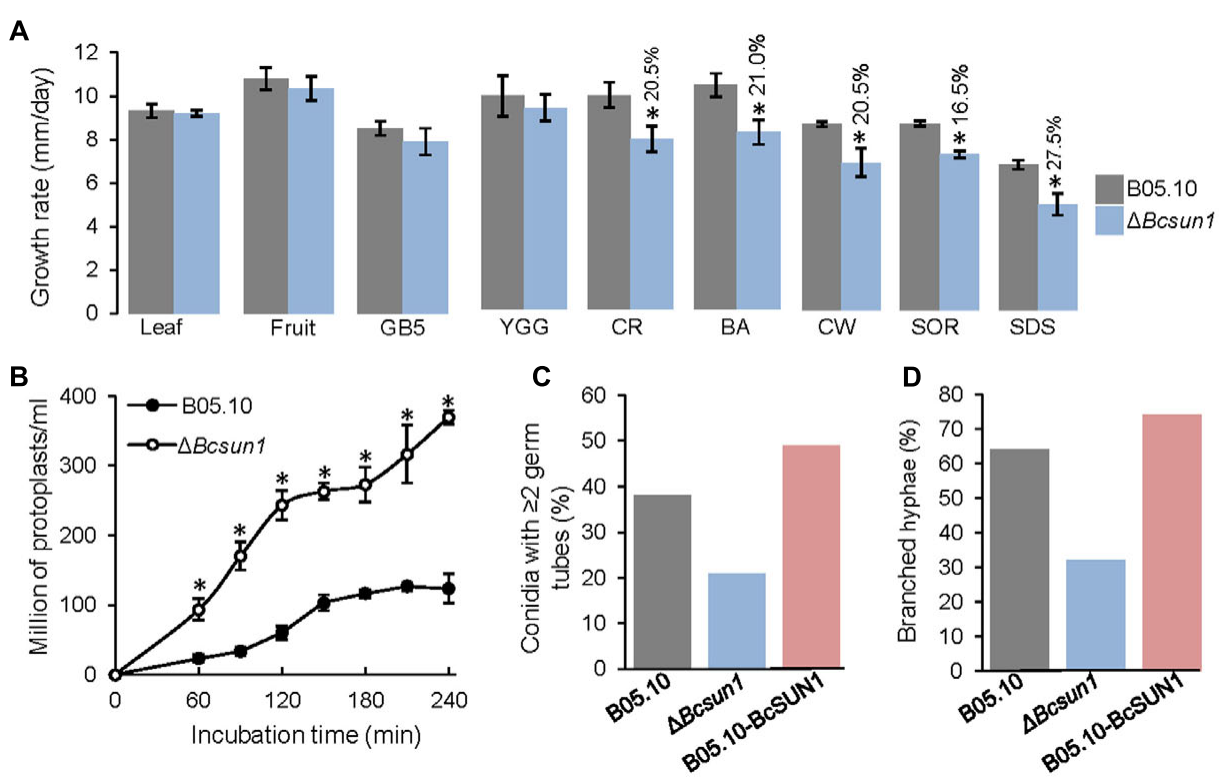

FIGURE 2 | Role of BcSUN1 in cell wall integrity. (A) Growth rate of the indicated strains in various media: $6 \%$ tomato leaf extract (Leaf), 25\% tomato fruit extract (Fruit), minimal medium (GB5), rich medium (YGG), YGG + 0.005\% congo red (CR), YGG + 0.4\% boric acid (BA), YGG + 0.05\% Calcofluor white (CW), YGG + 1 M Sorbitol (SOR), or YGG $+0.02 \%$ SDS (SDS). Results are shown as mean \pm SD for 9 biological replicates. Asterisks indicate a statistically significant difference (by $t$-test, $p=0.05$ ) between the wild type and the mutant in a given medium, and the percentage of reduction in growth rate for the mutant, as compared to the wild type, is indicated above bars. (B) Production of protoplasts (mean $\pm \mathrm{SD}, n=3$ ) from the indicated strains when treated with a cocktail of cell wall degrading enzymes. (C) Percentage of germinated conidia with two or more germ tubes at $16 \mathrm{~h}$ after inoculation in YGG medium ( $n \geq 100$ ). (D) Percentage of hyphae with two or more ramifications at $16 \mathrm{~h}$ after inoculation in the same medium $(n \geq 100)$.

obtained showed a significant reduction in both features for the mutant strains, relative to the wild type. The role of BcSUN1 in the production of sclerotia was also analyzed, and the results showed a significant increase in the number of these survival structures in the mutant strains, as well as a slight reduction in the number of sclerotia for the BcSUN1-overexpressing strain B05.10-BcSUN1 (Figures 4E,F). Taken together, these results suggest a role of $\mathrm{BcSUN1}$ in the production of $B$. cinerea reproductive structures.

\section{BcSUN1 Is a Secreted Protein, but Is Also Weakly Bound to the Cell Surface}

BcSUN1 has previously been identified as a component of B. cinerea secretome (Espino et al., 2010; González et al., 2014; González-Fernández et al., 2014) and was more abundant in the extracellular medium when the $O$-glycosylation machinery was altered by mutation of the Bcpmt1 gene (González et al., 2014). On the other hand, as discussed above, BcSUN1 plays a role in the cell wall. Its $S$. cerevisiae homologues SUN4, UTH1 and SIM1 have been reported to have having multiple cellular locations, either in the cell wall, the extracellular space, or in the mitochondria (Kuznetsov et al., 2013).

To study the putative binding of BcSUN1 to the cell wall and/or the ECM, the B05.10-BcSUN1 strain, which expressed a version of BcSUN1 bearing a c-myc epitope, was grown on YGG-L medium for $16 \mathrm{~h}$ and three fractions were recovered representing (i) the soluble extracellular proteins secreted to the culture medium, (ii) the proteins associated to the mycelium that could be released in presence of high salt, and (iii) the proteins extracted from the mycelium with Laemmli sample buffer. Salt treatment can release proteins weakly associated to the fungal cell wall and/or the matrix by van der Waals interactions, hydrogen bonds, and hydrophobic or ionic interactions (Jamet et al., 2008). The same three protein fractions isolated from the wild type strain (B05.10) cultures, as well as proteins precipitated from the un-inoculated medium (YGG-low) were used as negative controls. When proteins were fractionated by SDS-PAGE (Figure 5A) and BcSUN1 was visualized by western blot (Figure 5B), three different isoforms were found with apparent molecular weights of 25,50 , and $75 \mathrm{kDa}$, although the expected size for the recombinant polypeptide is $48 \mathrm{kDa}$. The three isoforms were found in the culture medium fraction, while only the 50 and $75 \mathrm{kDa}$ proteins were released from the mycelium surface by the salt treatment (Figure 5B). By considering all the bands obtained in the blots, BcSUN1 was mainly distributed, in almost equal parts, between the extracellular and the salt-extractable fractions (Figure 5B). As previously reported (González et al., 2014), no bands were seen in the negative controls (data not shown).

\section{BcSUN1 Is Required for Full Virulence}

To study the effect of the mutation of Bcsun 1 on fungal virulence, infections were carried out on detached leaves from various plant species. The $\Delta B$ csun 1 mutants showed, in the first place, a reduction in the number of inoculations actually producing a spreading lesion when tomato or tobacco leaves were inoculated 

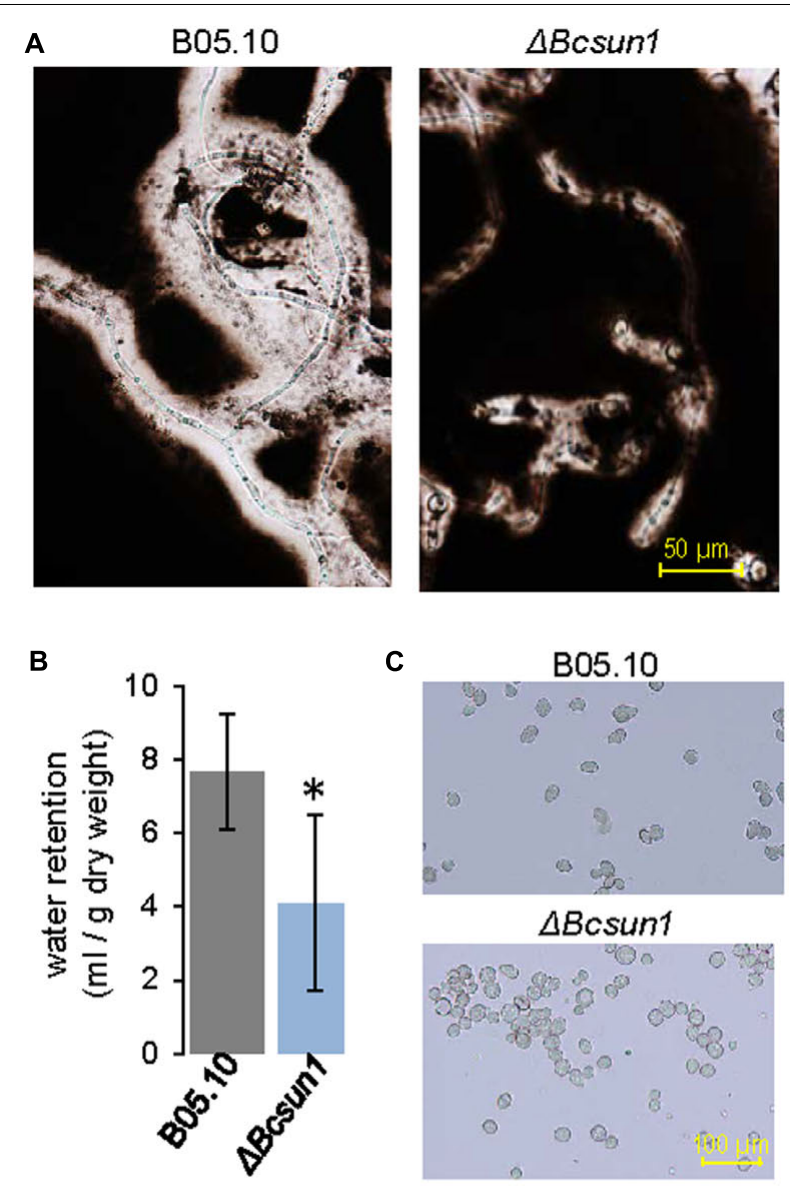

C

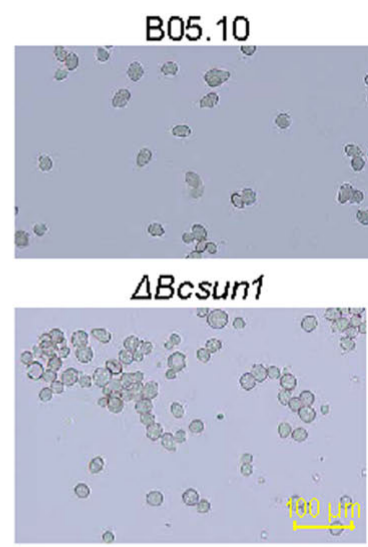

D
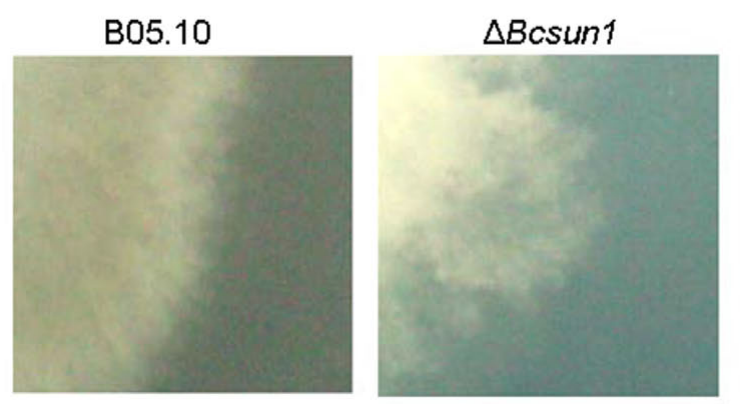

FIGURE 3 | Lack of BcSUN1 induces cell surface alterations. (A) ECM displayed by the $\Delta B c s u n 1$ mutant, as compared with the wild type (B05.10), detected by negative India ink staining of conidia germinated in PDB medium for 3 days. (B) Water retention capacity (mean $\pm \mathrm{SD} ; n=3$ ) of the two strains grown on YGG medium for 3 days. (C) Aggregation of $\Delta B c s u n 1$ mutant spores, as compared with the wild type (B05.10). (D) Differences in the morphology of the colony borders for the indicated strain when grown in MEA for 3 days.

with agar plugs (Table 2 ). Such a reduction in the proportion of expanding lesions, however, was not observed in the case of bean leaves inoculated with agar plugs, or in any host plant tested when inoculations were carried out with conidia. When the growth rate of the expanding lesions was measured, a significant reduction was observed for the $\Delta B \operatorname{csun} 1$ mutants
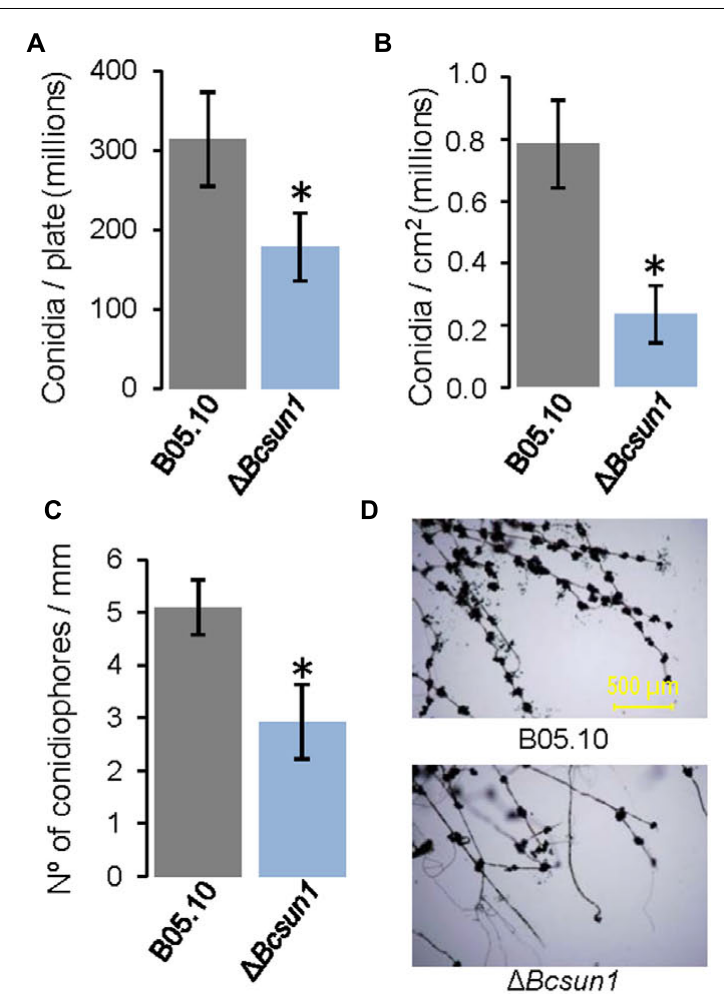

E

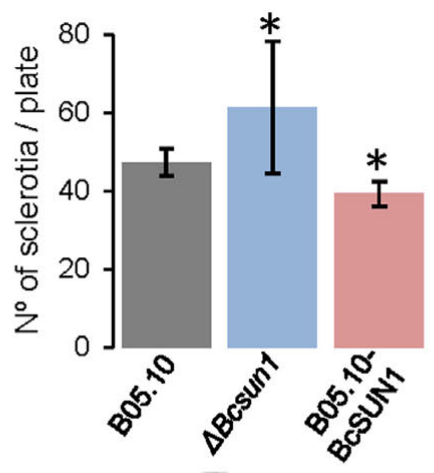

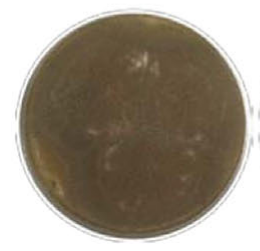

B05.10
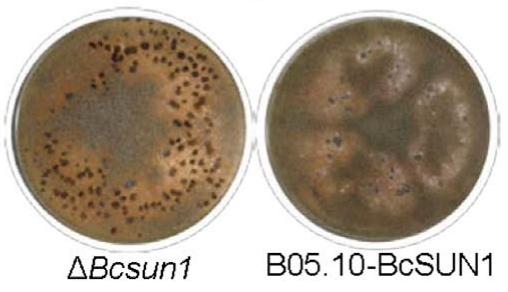

FIGURE 4 | Production of reproductive structures by the $\Delta B$ csun1 mutant. (A) Amount of conidia produced by the indicated strains in $25 \%$ tomato plates growing for 5 days, subjected to $12 \mathrm{~h}$ of near-UV light and maintained in the dark for 10 additional days (mean $\pm \mathrm{SD} ; n=3$ ). (B) Amount of conidia (mean $\pm \mathrm{SD} ; n=9$ ) collected from infected tobacco leaves at 10 days after inoculation. (C) Number of conidiophores along hyphae (mean $\pm \mathrm{SD} ; n=15$ ), produced by the indicated strains growing from YGG-agar plugs over sterile microscope slides after 10 days of incubation. (D) Images of conidiophores counted in (C). (E) Number of sclerotia produced (mean $\pm \mathrm{SD} ; n=3$ ) after 20 days of growth in 25\% tomato plates under continuous darkness. (F) Images of the plates from which the data in (E) were taken. Asterisk on bars indicate a statistically significant difference with the wild type (B05.10). 


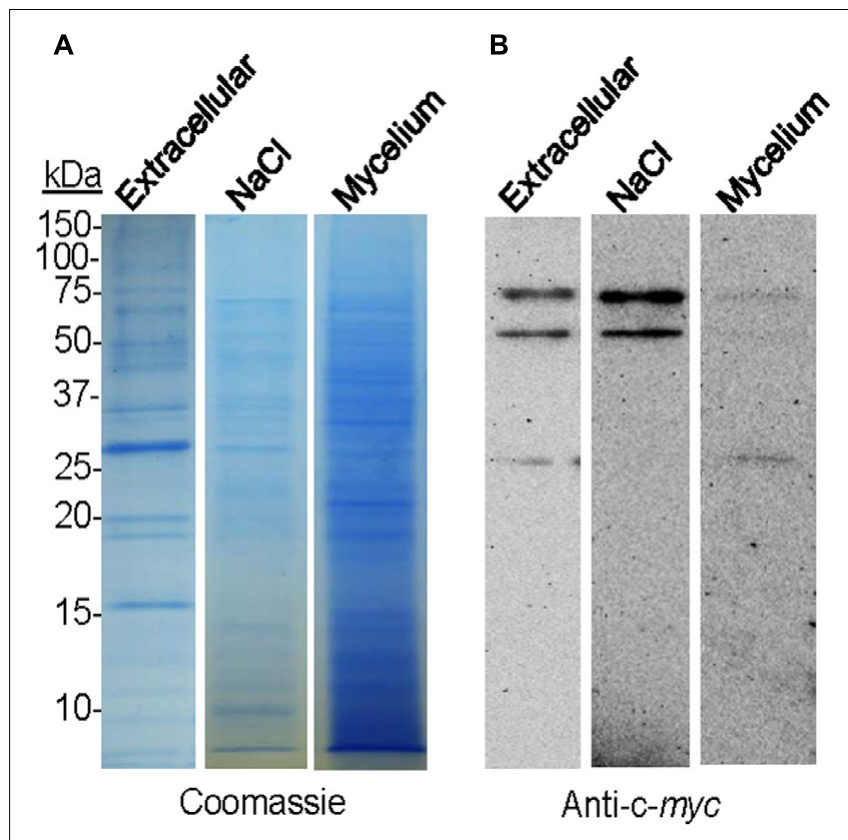

FIGURE 5 | Localization of BcSUN1. (A) SDS-PAGE (Coomassie) comparing the amount of total proteins precipitated from the culture medium (Extracellular), extracted with $\mathrm{NaCl}$ from the mycelium ( $\mathrm{NaCl})$, or extracted from the mycelium with Laemmli sample buffer (Mycelium) in cultures of the B05.10-BcSUN1 strain. The amounts of proteins loaded were those contained in $1 \mathrm{ml}$ of medium (1/30 of total from culture), $0.75 \mathrm{ml}$ of salt-solubilized suspension (1/11 of total from culture), and those extracted from $15 \mathrm{mg}$ of mycelium with Laemmli sample buffer (1/33 of total from culture). (B) Western blot (anti-c-myc) comparing the amount of recombinant BcSUN1 in the three fractions.

in the three host plant species when inoculations were carried out with agar plugs (Figure 6). In the case of inoculations with conidia, however, a significant reduction in expanding lesion growth rate was observed for the $\Delta B \operatorname{csun} 1$ mutants only on bean leaves, while lesions on tomato and tobacco leaves spread at the same rate for the mutants and the wild type. In all these tests, no significant differences were found for the B05.10-BcSUN1 strain, as compared to the wild type (not shown).

The initial stage of the infection process is characterized by adhesion of hyphae to the host surface. To analyze if the adherence of fungal hyphae to the plant surface is modified by Bcsun1 deletion, the adhesion of mutant strains to host tissue was examined by measuring the percentage of mycelium plugs detached from the surface of tobacco leaves after washing with water at $24 \mathrm{~h}$ post inoculation (Figure 7A), and by measuring the physical force that was necessary to detach individual plugs (Figure 7B). The $\Delta B \operatorname{csun} 1$ strains showed both an increase in the percentage of plugs that could be detached by washing and a decrease of the average adhesion force of individual plugs to the plant surface. Additionally, a microscopic analysis was done to examine if the deletion of the Bcsun1 gene induced changes in the number and/or the structure of infection cushions. The morphology of the cushions produced by the $\Delta B \operatorname{csun} 1$ mutants was similar to those generated by the wild type or the B05.10BcSUN1 strains (data not shown). However, the number of infection cushions was reduced between 50 to $70 \%$ in the mutants as compared to the wild type (Figure 7C).

Finally, the production of ROS in tobacco leaves during infection was analyzed, as it has been reported that UTH1 from $S$. cerevisiae and UvSUN2 from $U$. virens have a role in oxidativestress response (Bandara et al., 1998; Yu et al., 2015). An increase in the reddish-brown DAB precipitate was found in the lesions caused by the $\Delta B \operatorname{csun} 1$ strains, which was almost fourfold more intense than that produced by the wild type strain (Figure 7D). An increase in ROS production by the $\Delta B \operatorname{csun} 1$ mutants was also observed in vitro using a semi-quantitative method (Figure 7E). Furthermore, the addition of hydrogen peroxide to the culture medium reduced the growth rate of the $\Delta B \operatorname{csun} 1$ strains (by $14 \%$ ), indicating that ROS sensitivity seems also to be affected. All these changes in ROS production and tolerance may have a role in contributing to the lower virulence of the $\Delta B \operatorname{csun} 1$ mutants.

\section{DISCUSSION}

\section{The B. cinerea Genome Encodes Two SUN-Family Proteins}

$\beta$-Glucosidase SUN family members have been extensively studied in yeast and have been linked to diverse cellular functions such as cell wall biogenesis and septation, mitochondrial biogenesis, aging and DNA replication (Camougrand et al., 2000; Mouassite et al., 2000a; Velours et al., 2002; Hiller et al., 2007; Kuznetsov et al., 2013). BcSUN1 is a glycoprotein secreted by B. cinerea (Espino et al., 2010; González et al., 2014) that belongs to the Group-I of the SUN family, showing the highly conserved $C$-terminal region characteristic for this group of proteins. The search for other members of Group-I in the $B$. cinerea genome confirmed BcSUN1 as the single protein belonging to this group, but it revealed the existence of the Bcin07g06600.1 gene, which encodes a secreted protein of 530 amino acids with high homology with YMR244W from S. cerevisiae and Adg3 from S. pombe (Firon et al., 2007), both members of Group-II of the SUN family. This second member of the SUN family has been predicted to be GPI-anchored to the cell wall (de Groot et al., 2013) and to be highly O-glycosylated (González et al., 2012), features that are typical for Group-II proteins (Firon et al., 2007; Gastebois et al., 2013). The presence of a single protein from each group of the SUN family is considered characteristic for euascomycetes (Firon et al., 2007; de Groot et al., 2009; de Groot et al., 2013; Gastebois et al., 2013), while in yeasts the number of Group-I members can mount up to four, as in S. cerevisiae (Firon et al., 2007).

SUN family proteins have barely been experimentally characterized in filamentous fungi. AfSUN1 from A. fumigatus is the only Group-I protein studied so far, and it was shown to have a unique hydrolytic activity on $\beta$-1,3-glucan (Gastebois et al., 2013) which has resulted in classifying it in a new CAZY class, GH132. The high similarity of BcSUN1 to AfSUN1 suggests that the $B$. cinerea protein may also display this enzymatic 
TABLE 2 | Percentage of inoculations with the $\Delta B c s u n 1$ mutants resulting in spreading infections.

\begin{tabular}{|c|c|c|c|c|c|c|}
\hline & \multicolumn{2}{|c|}{ Bean leaves $(n=15)$} & \multicolumn{2}{|c|}{ Tomato leaves $(n=16)$} & \multicolumn{2}{|c|}{ Tobacco leaves $(n \geq 19)$} \\
\hline & Plugs & Conidia & Plugs & Conidia & Plugs & Conidia \\
\hline B05.10 & 100 & 100 & 86.7 & 100 & 91,7 & 100 \\
\hline$\Delta$ Bcsun 1.1 & 100 & 100 & 66.7 & 100 & 47.4 & 100 \\
\hline$\Delta B \operatorname{csun} 1.2$ & 100 & 100 & 66.7 & 100 & 30.0 & 100 \\
\hline B05.10-BcSUN1 & 100 & 100 & 100 & 100 & 89.5 & 100 \\
\hline
\end{tabular}

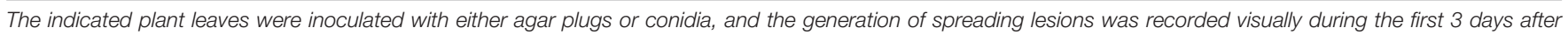
inoculation.

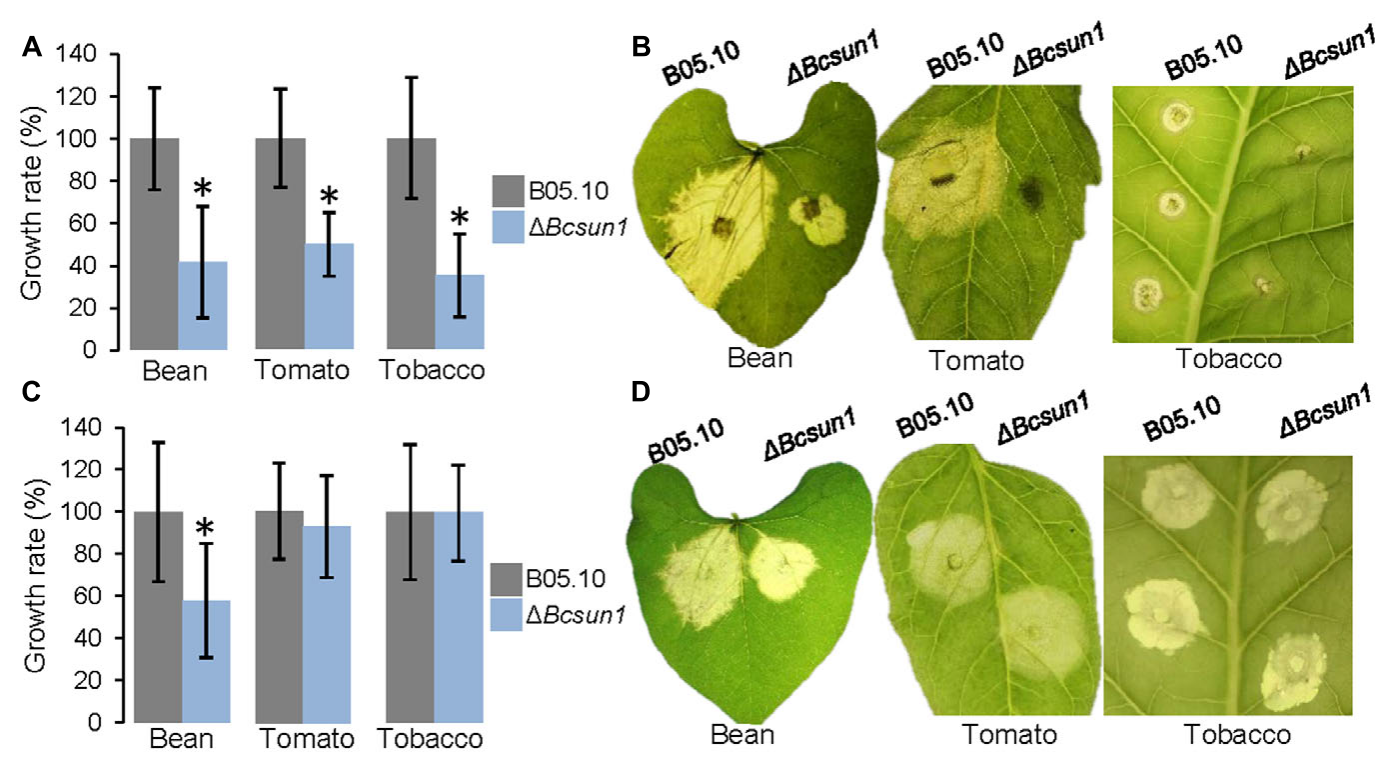

FIGURE 6 | Infection of different plant hosts with the $\mathbf{\Delta}$ Bcsun 1 mutants. (A) Growth rates (mean \pm SD; $n \geq 10$ ) of the infections caused by the mutant and the wild type on bean, tomato, or tobacco leaves, when inoculated with mycelium plugs. (B) Example images of the infections in (A) at 5 days after inoculation. (C) Same as in (A) but in this case inoculations were carried out with $5-\mu$ l drops of TGGK containing $5 \times 10^{6}$ conidia/ml. (D) Example images of the infections in (C) at 5 days after inoculation.

activity. However, our attempts to purify BcSUN1 from the strain B05.10-BcSUN1, in order to confirm its enzymatic activity, were unsuccessful.

\section{BcSUN1 Plays a Key Role in Maintaining the Cell Wall and Extracellular Matrix}

Previous analysis of $B$. cinerea secretomes obtained under different growth conditions, revealed BcSUN1 as a protein secreted by old mycelium grown on minimal and rich media (González et al., 2014; González-Fernández et al., 2014), but also as a member of the early secretome (Espino et al., 2010). Transcriptional analysis of conidial germination on wax-coated surfaces showed that Bcsun 1 expression was induced already in the first hour of conidial germination, and its level remained constant at least for the first $15 \mathrm{~h}$ after inoculation (Leroch et al., 2013). In the present work, we corroborated the expression of the Bcsun1 gene at the early stages after inoculation, both in axenic culture and in planta, and observed a continuous increase as the infection progresses, a pattern clearly consistent with a role in the morphogenesis and mycelial growth, as has been described for AfSUN1 (Gastebois et al., 2013).

The use of cell wall perturbing agents caused a reduction in the growth rates of $\Delta B \operatorname{csun} 1$ mutants (Figure 2A). This was the case for congo red, which blocks lateral interaction between glucan chains causing loss of cell wall rigidity (Kopecka and Gabriel, 1992; Ram and Klis, 2006), and Calcofluor white, which binds to chitin and interferes with its polymerization preventing the interactions between chitin and glucans (Roncero et al., 1988; Ram and Klis, 2006). $\Delta$ Bcsun 1 mutants also grew poorly in medium supplemented with boric acid (Figure 2A), which in C. albicans suppresses hyphal growth (De Seta et al., 2009) and in $S$. cerevisiae leads to the synthesis of irregular cell wall protuberances and the formation of irregular, chitin-rich septa (Schmidt et al., 2010). Finally, growth on high levels of sorbitol also resulted in growth reduction of the $\Delta B$ csun 1 mutants (Figure 2A). This sugar alcohol is used frequently to stabilize osmotically damaged cell walls, but it may also increase glycerol production causing a reduction in the synthesis of cell wall components (Gorka-Niec et al., 2010). These findings strongly 

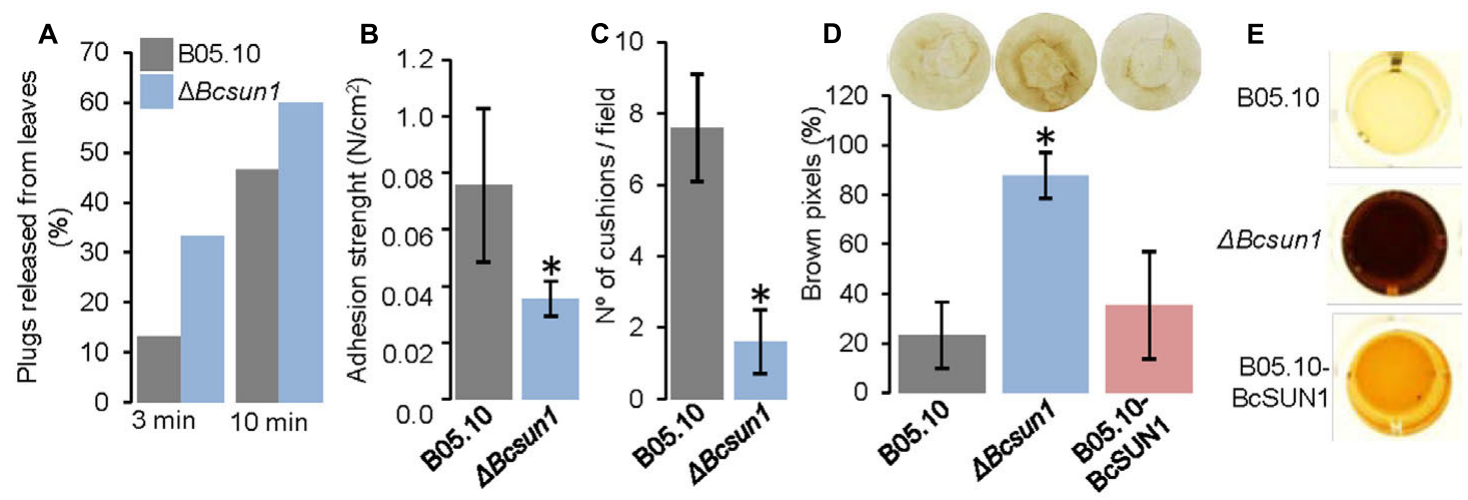

FIGURE 7 | Surface interaction between knockout Bcsun1 mutants and plant host. (A) Percentage of plugs released from tobacco leaves by washing with water (for the times indicated at the bottom) at $24 \mathrm{~h}$ after inoculation $(n \geq 15)$. (B) Adhesion strength of mycelium plugs to tobacco leaves after $24 \mathrm{~h}$ of incubation (mean $\pm \mathrm{SD} ; n=15$ ). (C) Number of infection cushions produced by the indicated strains from agar plugs on glass slides. The data correspond to the average number of cushion determined from 10 microscopic fields randomly chosen. (D) Production of $\mathrm{H}_{2} \mathrm{O}_{2}$ (as detected with DAB) in infected tobacco leaves, $36 \mathrm{~h}$ after inoculation with conidia of the indicated strains. Upper panel shows an example of the results, and lower panel shows a semi-quantification of $\mathrm{H}_{2} \mathrm{O}_{2}$ produced, expressed as the percentage of brown pixels in a circumference of constant area (calculated with the software Fiji, mean $\pm \mathrm{SD} ; n=5$ ). (E) Secretion of $\mathrm{H}_{2} \mathrm{O}_{2}$ by the indicated strains grown for 4 days in YGG medium, detected with DAB.

suggest that BcSUN1 may play a key role in the metabolism of the cell wall, since its absence in the mutants results in weaker walls. Additional evidence comes from the increased sensitivity of the mutant strains to SDS (Figure 2A), an anionic detergent that induces lysis of cells with fragile cell walls (Shimizu et al., 1994), and from the higher sensitivity to protoplastforming lytic enzymes (Figure 2B). Moreover, the changes in the hyphal branching pattern observed for the $\Delta B c s u n 1$ mutants (Figures 2C,D) also suggest modifications in cell septation and cell wall remodeling.

A role of SUN family proteins in cell wall biogenesis has also been described in other organisms. In the yeast $S$. cerevisiae, the four $S$. cerevisiae proteins act by remodeling the cell wall (Kuznetsov et al., 2013). In fact, knockout mutants in the UTH1 gene showed similar sensitivity to cell wall modifying substances (Kuznetsov et al., 2013) as reported here for $\Delta B c s u n 1$ mutants, and the reduction in the number of protoplasts generated from the UTH1 mutant strain has been related with an increase in $\beta$-1,6-glucan and chitin composition of the yeast cell wall (Ritch et al., 2010). SUN41 from C. albicans is also involved in morphogenesis, cell wall biogenesis and is necessary during yeast branching (Hiller et al., 2007). WMSU1 from Williopsis saturnus has been reported to be involved in cell wall metabolism (Guyard et al., 2000). Finally, PSU1 from S. pombe plays a critical role in cell separation (Omi et al., 1999; de Groot et al., 2007). In filamentous fungi, the deletion of AfSUN1 also caused alterations on the mycelium growth and hyphal morphogenesis, although no differences were reported/observed in the cell wall composition of the mutant strain (Gastebois et al., 2013).

Botrytis cinerea produces a prominent ECM involved in the adhesion to the host tissues (Doss, 1999; Cooper et al., 2000; Gil-ad et al., 2002; Doss et al., 2003). ECM was greatly reduced in $\Delta B$ csun 1 strains (Figure $\mathbf{3 A}$ ), which resulted in a reduced capacity to retain water (Figure $\mathbf{3 B}$ ). This may be a consequence of a reduced or weaker cell wall, since an altered glucan-chitin network may have less potential sites for binding to or interaction with the ECM components, but BcSUN1 itself may also be relevant for linking ECM components. In this context, it is interesting that the SUN41 protein from C. albicans has been proposed to play an important role in biofilm formation (Hiller et al., 2007; Norice et al., 2007).

The alterations in the $\Delta B \operatorname{csun} 1$ mutants regarding conidia and sclerotia production, conidia aggregation (Figure 3C), or colony morphology, may all be consequences of an altered cell wall and/or ECM. The aggregation of A. fumigatus germinating conidia, for example, is dependent on cell wall $\alpha$-1,3-glucans and may be prevented by the addition of $\alpha$-1,3-glucanase (Fontaine et al., 2010), and similar phenotypic features have been reported for a $B$. cinerea mutant in the gene $B c p m r 1$ displaying an altered cell wall (Plaza et al., 2015).

\section{BcSUN1 Is Associated with the Cell Surface and Is Also Secreted}

The c-myc-tagged version of BcSUN1 was identified in the secretome of the B05.10-BcSUN1 strain in three isoforms (Figure 5B), with molecular weights that differ from the expected size for the recombinant protein (González et al., 2014). Glycosylation may contribute to this heterogeneity, as not only $74 \mathrm{O}$-glycosylation sites are predicted for the protein (González et al., 2012), but it has also been experimentally shown to contain mannose residues linked by $\alpha 1-2$ or $\alpha 1-3$ glycosidic bonds (González et al., 2014). Additionally, the present study detected BcSUN1 both in the extracellular media as a soluble protein and also associated to the cell wall (Figure 5). Such dual localization has also been described for UTH1, SUN4 and SIM1 (Kuznetsov et al., 2013), and similar findings were reported for C. albicans SUN41 and SUN42 proteins (Hiller et al., 2007; Sorgo et al., 2010). The $S$. pombe psu1 protein, however, is covalently 
bound to the glucan network of the cell wall via a mild alkalisensitive phosphodiester bridge (de Groot et al., 2007). The cell-wall association of BcSUN1 is consistent with a role in cell wall metabolism, as discussed above, and it may play a role there in remodeling the extracellular structures including cell wall and ECM.

\section{BcSUN1 Is a Virulence Factor}

$B c s u n 1$ is expressed from the very early stage of fungus-plant interaction, and Bcsun1 mRNA levels increase as the lesions become necrotic (Figure 1B). Previously, Smith et al. (2014) identified Bcsun 1 as one of the genes induced in planta during infection of Solanum lycopersicoides leaves. Altogether, these results suggested a role of BcSUN1 in fungal pathogenesis. Indeed BcSUN1 is involved in the adhesion of the mycelium to the host surface during infection (Figure 7), most probably by altering the properties of the ECM and thus changing its adhesive capacity. The chemical nature of these alterations remains to be investigated. The reduced adherence of the $\Delta B c s u n 1$ mutants could explain the lower capacity of the mutants to initiate a successful infection (Table 2), and this effect may be more prominent in natural infections in the field, where a single conidium landing on the plant surface is the predominant source of inoculum. We also found that Bcsun1 mutants showed a reduced production of infection cushions (Figure $7 \mathrm{C}$ ), which are specialized, dense and highly branched structures that play a critical role in mycelium-derived infections (Choquer et al., 2007), as well as an overall reduced virulence on all plant hosts tested (Figure 6). Moreover, $\Delta B \operatorname{csun} 1$ mutants are affected in the production of conidia and sclerotia (Figure 4), which may in turn affect the dispersal of the pathogen. Finally, the $\Delta B \operatorname{csun} 1$ mutants showed an enhanced production of hydrogen peroxide

\section{REFERENCES}

Altschul, S. F., Madden, T. L., Schaffer, A. A., Zhang, J., Zhang, Z., Miller, W., et al. (1997). Gapped BLAST and PSI-BLAST: a new generation of protein database search programs. Nucleic Acids Res. 25, 3389-3402. doi: 10.1093/nar/25.17.3389

Bandara, P. D., Flattery-O'Brien, J. A., Grant, C. M., and Dawes, I. W. (1998). Involvement of the Saccharomyces cerevisiae UTH1 gene in the oxidative-stress response. Curr. Genet. 34, 259-268. doi: 10.1007/s002940050395

Benito, E. P., ten Have, A., van't Klooster, J. W., and Van Kan, J. A. L. (1998). Fungal and plant gene expression during synchronized infection of tomato leaves by Botrytis cinerea. Eur. J. Plant Pathol. 104, 207-220. doi: 10.1023/A: 1008698116106

Brito, N., Espino, J. J., and González, C. (2006). The endo-ß-1,4-xylanase Xyn11A is required for virulence in Botrytis cinerea. Mol. Plant Microbe Interact. 19, 25-32. doi: 10.1094/MPMI-19-0025

Camougrand, N. M., Mouassite, M., Velours, G. M., and Guérin, M. G. (2000). The "SUN" Family: UTH1, an ageing gene, is also involved in the regulation of mitochondria biogenesis in Saccharomyces cerevisiae. Arch. Biochem. Biophys. 375, 154-160. doi: 10.1006/abbi.1999.1655

Cappellaro, C., Mrsa, V., and Tanner, W. (1998). New potential cell wall glucanases of Saccharomyces cerevisiae and their involvement in mating. J. Bacteriol. 180, 5030-5037.

Choquer, M., Fournier, E., Kunz, C., Levis, C., Pradier, J. M., Simon, A., et al. (2007). Botrytis cinerea virulence factors: new insights into a necrotrophic and polyphageous pathogen. FEMS Microbiol. Lett. 277, 1-10. doi: 10.1111/j.15746968.2007.00930.x in axenic culture and in planta (Figure 7), which may also contribute to their altered virulence. In conclusion, we report here for the first time the involvement of a protein from the $\beta$-glucosidase SUN family in the virulence of a phytopathogenic fungus. Since this family has been found only in ascomycetes, these proteins represent a promising novel target to develop new control strategies against B. cinerea.

\section{AUTHOR CONTRIBUTIONS}

All authors participated in the design of the experiments as well as the analysis/evaluation of the results. AP-H and MG drafted the initial manuscript and all authors participated in the editing and approved its final version.

\section{ACKNOWLEDGMENTS}

Support for this research was provided by grants from Fundación CajaCanarias (CTCEPLA07) and Ministerio de Educación y Ciencia (AGL2010-22222). MG was financed by EMBO for a short stay at Wageningen University for the generation of Bcsun1 knockout mutants and by Fundación CajaCanarias (CTCEPLA07).

\section{SUPPLEMENTARY MATERIAL}

The Supplementary Material for this article can be found online at: http://journal.frontiersin.org/article/10.3389/fmicb. 2017.00035/full\#supplementary-material

Cooper, L. L. D., Oliver, J. E., De Vilbiss, E. D., and Doss, R. P. (2000). Lipid composition of the extracellular matrix of Botrytis cinerea germlings. Phytochemistry 53, 293-298. doi: 10.1016/S0031-9422(99)00495-1

Dahmann, C., Diffley, J. F., and Nasmyth, K. A. (1995). S-phase-promoting cyclin-dependent kinases prevent re-replication by inhibiting the transition of replication origins to a pre-replicative state. Curr. Biol. 5, 1257-1269. doi: 10.1016/S0960-9822(95)00252-1

de Groot, P. W., Martínez, A. I., and Castillo, L. (2013). “A genomic inventory of cell wall biosynthesis in the ubiquitous plant pathogen Botrytis cinerea," in The Fungal Cell Wall, ed. H. M. Mora-Montes (New York, NY: Nova Science Publishers), 91-129.

de Groot, P. W., Yin, Q. Y., Weig, M., Sosinska, G. J., Klis, F. M., and de Koster, C. G. (2007). Mass spectrometric identification of covalently bound cell wall proteins from the fission yeast Schizosaccharomyces pombe. Yeast 24, 267-278. doi: 10.1002/yea.1443

de Groot, P. W. J., Brandt, B. W., Horiuchi, H., Ram, A. F. J., de Koster, C. G., and Klis, F. M. (2009). Comprehensive genomic analysis of cell wall genes in Aspergillus nidulans. Fungal Genet. Biol. 46, S72-S81. doi: 10.1016/j.fgb.2008. 07.022

De Seta, F., Schmidt, M., Vu, B., Essmann, M., and Larsen, B. (2009). Antifungal mechanisms supporting boric acid therapy of Candida vaginitis. J. Antimicrob. Chemother. 63, 325-336. doi: 10.1093/jac/dkn486

Dean, R., van Kan, J. A., Pretorius, Z. A., Hammond-Kosack, K. E., Di Pietro, A., Spanu, P. D., et al. (2012). The Top 10 fungal pathogens in molecular plant pathology. Mol. Plant Pathol. 13, 414-430. doi: 10.1111/j.1364-3703.2011. 00783.x 
Doss, R. P. (1999). Composition and enzymatic activity of the extracellular matrix secreted by germlings of Botrytis cinerea. Appl. Environ. Microbiol. 65, 404-408.

Doss, R. P., Deisenhofer, J., Krug von Nidda, H. A., Soeldner, A. H., and McGuire, R. P. (2003). Melanin in the extracellular matrix of germlings of Botrytis cinerea. Phytochemistry 63, 687-691. doi: 10.1016/S0031-9422(03) 00323-6

Doss, R. P., Potter, S. W., Soeldner, A. H., Christian, J. K., and Fukunaga, L. E. (1995). Adhesion of germlings of Botrytis cinerea. Appl. Environ. Microbiol. 61, 260-265.

Du, L. L., and Novick, P. (2002). Paglp, a novel protein associated with protein kinase Cbklp, is required for cell morphogenesis and proliferation in Saccharomyces cerevisiae. Mol. Biol. Cell 13, 503-514. doi: 10.1091/mbc.01-070365

Espino, J. J., Gutiérrez-Sánchez, G., Brito, N., Shah, P., Orlando, R., and González, C. (2010). The Botrytis cinerea early secretome. Proteomics 10, 3020-3034. doi: 10.1002/pmic.201000037

Firon, A., Aubert, S., Iraqui, I., Guadagnini, S., Goyard, S., Prevost, M. C., et al. (2007). The SUN41 and SUN42 genes are essential for cell separation in Candida albicans. Mol. Microbiol. 66, 1256-1275. doi: 10.1111/j.1365-2958. 2007.06011.x

Fontaine, T., Beauvais, A., Loussert, C., Thevenard, B. T., Fulgsang, C., Ohno, N., et al. (2010). Cell wall $\beta$-1,3glucans induce the aggregation of germinating conidia of Aspergillus fumigatus. Fungal Genet. Biol. 47, 707-712. doi: 10.1016/ j.fgb.2010.04.006

Gastebois, A., Aimanianda, V., Bachellier-Bassi, S., Nesseir, A., Firon, A., Beauvais, A., et al. (2013). SUN proteins belong to a novel family of beta-(1,3)glucan-modifying enzymes involved in fungal morphogenesis. J. Biol. Chem. 288, 13387-13396. doi: 10.1074/jbc.M112.440172

Gil-ad, N. L., Bar-Nun, N., and Mayer, A. M. (2002). The possible function of the glucan sheath of Botrytis cinerea: effects on the distribution of enzyme activities. FEMS Microbiol. Lett. 199, 109-113. doi: 10.1111/j.1574-6968.2001. tb10659.x

González, C., Brito, N., and Sharon, A. (2015). "Infection process and fungal virulence factors," in Botrytis- the Fungus, the Pathogen and Its Management in Agricultural Systems, eds S. Fillinger and Y. Elad (Berlin: Springer), 229-246.

González, M., Brito, N., Frias, M., and González, C. (2013). Botrytis cinerea protein O-mannosyltransferases play critical roles in morphogenesis, growth, and virulence. PLOS ONE 8:e65924. doi: 10.1371/journal.pone. 0065924

González, M., Brito, N., and González, C. (2012). High abundance of Serine/Threonine-rich regions predicted to be hyper-O-glycosylated in the extracellular proteins coded by eight fungal genomes. BMC Microbiol. 12:213. doi: 10.1186/1471-2180-12-213

González, M., Brito, N., and González, C. (2014). Identification of glycoproteins secreted by wild-type Botrytis cinerea and by protein-O-mannosyltransferase mutants. BMC. Microbiol. 14:254. doi: 10.1186/s12866-014-0254-y

González-Fernández, R., Aloria, K., Valero-Galván, J., Redondo, I., Arizmendi, J. M., and Jorrin-Novo, J. V. (2014). Proteomic analysis of mycelium and secretome of different Botrytis cinerea wild-type strains. J. Proteomics 97, 195-221. doi: 10.1016/j.jprot.2013.06.022

Gorka-Niec, W., Perlinska-Lenart, U., Zembek, P., Palamarczyk, G., and Kruszewska, J. S. (2010). Influence of sorbitol on protein production and glycosylation and cell wall formation in Trichoderma reesei. Fungal Biol. 114, 855-862. doi: 10.1016/j.funbio.2010.07.010

Guyard, C., Magliani, W., Polonelli, L., and Cailliez, J. C. (2000). Yeast killer toxins. J. Mycol. Med. 10, 9-20.

Hiller, E., Heine, S., Brunner, H., and Rupp, S. (2007). Candida albicans Sun41p, a putative glycosidase, is involved in morphogenesis, cell wall biogenesis, and biofilm formation. Eukaryot. Cell 6, 2056-2065. doi: 10.1128/EC. 00285-07

Hiller, E., Zavrel, M., Hauser, N., Sohn, K., Burger-Kentischer, A., Lemuth, K., et al. (2011). Adaptation, adhesion and invasion during interaction of Candida albicans with the host. Focus on the function of cell wall proteins. Int. J. Med. Microbiol. 301, 384-389. doi: 10.1016/j.ijmm.2011.04.004

Jamet, E., Boudart, G., Borderies, G. I., Charmont, S., Lafitte, C., Rossignol, M., et al. (2008). "Isolation of plant cell wall proteins," in 2D PAGE: Sample Preparation and Fractionation, ed. A. Posch (New York City, NY: Humana Press), 187-201.
Kennedy, B. K., Austriaco, N. R. Jr., Zhang, J., and Guarente, L. (1995). Mutation in the silencing gene SIR4 can delay aging in S. cerevisiae. Cell 80, 485-496. doi: 10.1016/0092-8674(95)90499-9

Kopecka, M., and Gabriel, M. (1992). The influence of congo red on the cell wall and (1-3)-beta-D-glucan microfibril biogenesis in Saccharomyces cerevisiae. Arch. Microbiol. 158, 115-126. doi: 10.1007/BF00245214

Kuznetsov, E., Kucerová, H., Vachova, L. E., and Palková, Z. (2013). SUN Family proteins Sun4p, Uth1p and Simlp are secreted from Saccharomyces cerevisiae and produced dependently on oxygen level. PLoS ONE 8:e73882. doi: 10.1371/ journal.pone.0073882

Kwon-Chung, K. J., and Sugui, J. A. (2013). Aspergillus fumigatus: What makes the species a ubiquitous human fungal pathogen? PLoS Pathog. 9:e1003743. doi: 10.1371/journal.ppat.1003743

Laemmli, U. K. (1970). Cleavage of structural proteins during the assembly of the head of bacteriophage T4. Nature 227, 680-685. doi: 10.1038/227680a0

Laspidou, C. S., and Rittmann, B. E. (2002). A unified theory for extracellular polymeric substances, soluble microbial products, and active and inert biomass. Water Res. 36, 2711-2720. doi: 10.1016/S0043-1354(01)00414-6

Leroch, M., Kleber, A., Silva, E., Coenen, T., Koppenhofer, D., Shmaryahu, A., et al. (2013). Transcriptome profiling of Botrytis cinerea conidial germination reveals upregulation of infection-related genes during the pre-penetration stage. Eukaryot. Cell. 12, 614-626. doi: 10.1128/EC. 00295-12

Mouassite, M., Camougrand, N., Schwob, E., Demaison, G. V., Laclau, M., and Guerin, M. (2000a). The "SUN" family: yeast SUN4/SCW3 is involved in cell septation. Yeast 16, 905-919. doi: 10.1002/1097-0061(200007)16:10<905::AIDYEA584>3.0.CO;2-1

Mouassite, M., Guerin, M. G., and Camougrand, N. M. (2000b). The SUN family of Saccharomyces cerevisiae: the double knock-out of UTH1 and SIM1 promotes defects in nucleus migration and increased drug sensitivity. FEMS Microbiol. Lett. 182, 137-141. doi: 10.1111/j.1574-6968.2000. tb08887.x

Nelson, M. D., and Fitch, D. H. (2011). "Overlap extension PCR: an efficient method for transgene construction,” in Molecular Methods for Evolutionary Genetics, eds V. Orgogozo and M. Rockman (New York, NY: Humana Press), 459-470.

Norice, C. T., Smith, F. J. Jr., Solis, N., Filler, S. G., and Mitchell, A. P. (2007). Requirement for Candida albicans Sun41 in biofilm formation and virulence. Eukaryot. Cell. 6, 2046-2055. doi: 10.1128/EC.00314-07

Omi, K., Sonoda, H., Nagata, K., and Sugita, K. (1999). Cloning and characterization of psu1(+), a new essential fission yeast gene involved in cell wall synthesis. Biochem. Biophys. Res. Commun. 262, 368-374. doi: 10.1006/ bbrc.1999.1209

Pelissier, P., Camougrand, N., Velours, G., and Guérin, M. (1995). NCA3, a nuclear gene involved in the mitochondrial expression of subunits 6 and 8 of the Fo-F1 ATP synthase of S. cerevisiae. Curr. Genet. 27, 409-416. doi: 10.1007/ BF00311209

Plaza, V., Lagés, Y., Carvajal, M., Pérez-García, L. A., Mora-Montes, H. M., Canessa, P., et al. (2015). bcpmr1 encodes a P-type Ca2+/Mn2+-ATPase mediating cell-wall integrity and virulence in the phytopathogen Botrytis cinerea. Fungal Genet. Biol. 76, 36-46. doi: 10.1016/j.fgb.2015.01.012

Quidde, T., Buttner, P., and Tudzynski, P. (1999). Evidence for three different specific saponin-detoxifying activities in Botrytis cinerea and cloning and functional analysis of a gene coding for a putative avenacinase. Eur. J. Plant Pathol. 105, 273-283. doi: 10.1023/A:1008796006051

Ram, A. F. J., and Klis, F. M. (2006). Identification of fungal cell wall mutants using susceptibility assays based on Calcofluor white and Congo red. Nat. Protocols 1 , 2253-2256. doi: 10.1038/nprot.2006.397

Ritch, J. J., Davidson, S. M., Sheehan, J. J., and Austriaco, N. (2010). The Saccharomyces SUN gene, UTH1, is involved in cell wall biogenesis. FEMS Yeast Res. 10, 168-176. doi: 10.1111/j.1567-1364.2009. 00601.x

Roncero, C., Valdivieso, M. H., Ribas, J. C., and Duran, A. (1988). Effect of calcofluor white on chitin synthases from Saccharomyces cerevisiae. J. Bacteriol. 170, 1945-1949. doi: 10.1128/jb.170.4.1945-1949.1988

Schindelin, J., Arganda-Carreras, I., Frise, E., Kaynig, V., Longair, M., Pietzsch, T., et al. (2012). Fiji: an open-source platform for biological-image analysis. Nat. Methods 9, 676-682. doi: 10.1038/nmeth.2019 
Schmidt, M., Schaumberg, J. Z., Steen, C. M., and Boyer, M. P. (2010). Boric acid disturbs cell wall synthesis in Saccharomyces cerevisiae. Int. J. Microbiol. 2010:930465. doi: 10.1155/2010/930465

Schmittgen, T. D., and Livak, K. J. (2008). Analyzing real-time PCR data by the comparative C(T) method. Nat. Protoc. 3, 1101-1108. doi: 10.1038/nprot. 2008.73

Shimizu, J., Yoda, K., and Yamasaki, M. (1994). The hypo-osmolarity-sensitive phenotype of the Saccharomyces cerevisiae hpo2 mutant is due to a mutation in PKC1, which regulates expression of beta-glucanase. Mol. Gen. Genet. 242, 641-648. doi: 10.1007/BF00283417

Smith, J. E., Mengesha, B., Tang, H., Mengiste, T., and Bluhm, B. H. (2014). Resistance to Botrytis cinerea in Solanum lycopersicoides involves widespread transcriptional reprogramming. BMC Genomics 15:334. doi: 10.1186/14712164-15-334

Sorgo, A. G., Heilmann, C. J., Dekker, H. L., Brul, S., de Koster, C. G., and Klis, F. M. (2010). Mass spectrometric analysis of the secretome of Candida albicans. Yeast 27, 661-672. doi: 10.1002/yea.1775

ten Have, A., Espino, J. J., Dekkers, E., Sluyter, S. C. V., Brito, N., Kay, J., et al. (2010). The Botrytis cinerea aspartic proteinase family. Fungal Genet. Biol. 47, 53-65. doi: 10.1016/j.fgb.2009.10.008

van Kan, J. A., Stassen, J. H., Mosbach, A., van der Lee, T. A., Faino, L., Farmer, A. D., et al. (2016). A gapless genome sequence of the fungus Botrytis cinerea. Mol. Plant Pathol. 18, 75-89. doi: 10.1111/mpp.12384

van Kan, J. A. L., van't Klooster, J. W., Wagemakers, C. A. M., Dees, D. C. T., and van der Vlugt-Bergmans, C. J. B. (1997). Cutinase A of Botrytis cinerea is expressed, but not essential, during penetration of gerbera and tomato. Mol. Plant Microbe Interact. 10, 30-38. doi: 10.1094/MPMI.1997.10.1.30

Velours, G., Boucheron, C., Manon, S., and Camougrand, N. (2002). Dual cell wall/mitochondria localization of the SUN family proteins. FEMS Microbiol. Lett. 207, 165-172. doi: 10.1111/j.1574-6968.2002.tb11046.x
Viefhues, A., Schlathoelter, I., Simon, A., Viaud, M., and Tudzynski, P. (2015). Unraveling the function of the response regulator BcSkn7 in the stress signaling network of Botrytis cinerea. Eukaryot. Cell. 14, 636-651. doi: 10.1128/EC. 00043-15

Wessel, D., and Flügge, U. I. (1984). A method for the quantitative recovery of protein in dilute solution in the presence of detergents and lipids. Anal. Biochem. 138, 141-143. doi: 10.1016/0003-2697(84)90782-6

Yu, M., Yu, J., Hu, J., Huang, L., Wang, Y., Yin, X., et al. (2015). Identification of pathogenicity-related genes in the rice pathogen Ustilaginoidea virens through random insertional mutagenesis. Fungal Genet. Biol. 76, 10-19. doi: 10.1016/j. fgb.2015.01.004

Zhang, L., Thiewes, H., and van Kan, J. A. (2011). The D-galacturonic acid catabolic pathway in Botrytis cinerea. Fungal Genet. Biol. 48, 990-997. doi: 10.1016/j.fgb. 2011.06 .002

Conflict of Interest Statement: The authors declare that the research was conducted in the absence of any commercial or financial relationships that could be construed as a potential conflict of interest.

The reviewer AMR and handling Editor declared their shared affiliation, and the handling Editor states that the process nevertheless met the standards of a fair and objective review.

Copyright (C) 2017 Pérez-Hernández, González, González, van Kan and Brito. This is an open-access article distributed under the terms of the Creative Commons Attribution License (CC BY). The use, distribution or reproduction in other forums is permitted, provided the original author(s) or licensor are credited and that the original publication in this journal is cited, in accordance with accepted academic practice. No use, distribution or reproduction is permitted which does not comply with these terms. 